\title{
Trends in acute poisoning due to deliberate self-harm in the Southern Province of Sri Lanka
}

\author{
Ariyananda PL \\ Department of Medicine, Faculty of Medicine, University of Ruhuna, Galle \\ (Extract of the GMA oration delivered during the 2009 Annual Academic Sessions) \\ Correspondence: Professor PLAriyananda (ariyananda@sltnet.lk)
}

\section{Background}

Poisoning by deliberate ingestion of drugs and poisons is a serious medical problem in the world. Pesticide ingestion is the commonest mode of suicide in Asia with an estimated loss of around 300,000 lives every year $(1,2)$. In 1991 Sri Lanka had the dubious distinction of being the country with the highest suicide rate in the world (47/100,000 population). Even now statistics in Sri Lanka manifest an alarmingly high rate of suicide and as healthcare providers we have to be very much concerned about this situation and we should take every possible measure to reduce such unnecessary loss of life and the burden on health resources. Pesticide poisoning was listed as the $6^{\text {th }}$ common cause of hospital deaths in Sri Lanka in 1990s (3). However, there has been a $50 \%$ reduction in deaths due to pesticide poisoning during the past 12 years in SriLanka (4).

Pesticide poisoning is often intentional with a motive of self-harm. Unfortunately, as pesticides are highly toxic its ingestion carries a very high mortality. Besides pesticides, ingestion of yellow oleander (kaneru) is now known to cause high mortality in the North Central Province and in Hambantota District (5). Yellow oleander (kaneru) poisoning was first reported in Sri Lanka in 1979 and since then the number of patients reported to be taking yellow oleander has greatly increased (5). This year we have reported a case series of 115 patients who have taken oxalic acid or potassium permanganate or both when attempting deliberate self-harm resulting in 18 deaths (6). Drug overdose is a leading cause of hospital admission and in more 50\% instances the drug incriminated is paracetamol. Fortunately, deaths due overdose of paracetamol are rare. Poisoning due to accidental or homicidal causes is very rare. Accidental poisoning is usually seen amongst toddlers and the poisons taken are usually feebly toxic and rarely cause deaths.

\section{Our Research Collaborations}

In 2004, the National Health and Medical Research Council of Australia awarded a large grant to the South Asian Clinical Toxicology Research Collaboration (SACTRC) to set up a network for research in Clinical Toxicology in Sri Lanka. The Chief Investigator of this project is Professor Nicholas Buckley, Professor of Clinical Toxicology, University of New South Wales, Australia and the Project Director is Professor Andrew Dawson who holds professorial positions in University of Canberra and University of Newcastle in Australia, and in University of Peradeniya. I work as the Senior Collaborator of SACTRC for the Southern Province. SACTRC has nine centers in Sri Lanka and one in India which is located in Tamil Nadu in the city of Vellore. In the Southern Province SACTRC has centres in Galle and Matara. Research work that we are doing have been approved by the Ethical Review Committee of Sri Lanka Medical Association and that of Faculty of Medicine, University of Ruhuna.

\section{Epidemic of poisoning due to a washing powder containing oxalic acid and potassium permanganate (6)}

I will revisit the study of 115 patients with poisoning due to the washing powder containing oxalic acid and potassium permanganate. This washing powder is sold as twin sachet with one compartment containing $12.5 \mathrm{~g}$ of oxalic acid and other containing $1.2 \mathrm{~g}$ of potassium permanganate. It is a product that is manufactured and sold without the approval from regulatory authorities. It is sold under many trade names, of which one is 'Prinso' and it has a reputation for removing resistant patches of fungus from clothes and hence it is also called as 'Pus-kudu' in Sinhala. Data for this study was collected during the period January 2007 to September 2008 from four hospitals - Teaching Hospital - Karapitiya, General 
Hospital - Matara and District Hospitals in Deniyaya and Hiniduma. At Teaching Hospital Karapitiya out of 1995 patients admitted with self-poisoning during this period, 103 including 61 females were admitted after ingesting the washing powder accounting to $5.2 \%$ of cases admitted with self-poisoning. Among this cohort of cases the number of patients that swallowed oxalic acid alone was 51 with 13 deaths and the combination oxalic acid and potassium permanganate was 51 with five deaths giving a case fatality ratio of $25 \%$ and $10 \%$ respectively. There were no deaths among patients who had taken only potassium permanganate. Among 18 patients that died, 11 patients died within one hour of ingestion, even before reaching the hospital. A summary of findings in these patients that we reported in the Journal of Clinical Toxicology this year are given in the table below (6).

Postmortems were performed on 16 patients and all of them had superficial erosions of the oesophagus, nasopharynx and the larynx. Some had pale kidneys. One patient had cerebral oedema, another had bleeding in the pericardium and adrenal glands and two had congested lungs. The major contributor to deaths appears to be oxalic acid as no one died in the group that took only potassium permanganate. Given the fact that most deaths occurred within a short time, deaths could have been due to a cardiac cause possibly from severe hypocalcaemia, resulting from chelation of calcium by oxalic acid being one of the explanations. This has been reported in ethylene glycol poisonings (7). Incidence of poisoning by this washing powder has increased in the year 2008 compared to 2007 as shown in the figure 1 (6).

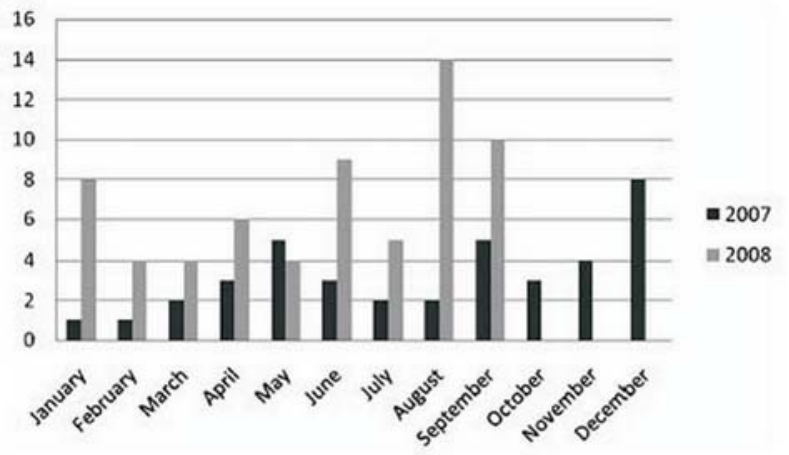

Figure 1 - Incidence of washing powder poisoning

Although this washing powder was available in the market for many years recent escalation in number of cases suggest some kind of 'trend setting' among the youth. A similar observation of 'trend setting' was noted with yellow oleander (kaneru) poisoning where the index case was reported in 1979 with subsequent escalation of cases to epidemic level numbering more than 1000 cases every year (5). Currently we are investigating to see whether media publicity has contributed to escalation of washing powder poisoning.

\section{Paraquat poisoning}

Paraquat is better known as GRAMOXONE (manufactured by SYNGENTA). It is a panherbicide. Paraquat has boosted agricultural crop yields in vast amounts and this is considered to be one of the biggest agricultural revolutions in the past century. However, ingestion of $20 \%$ paraquat in even in amounts exceeding $10 \mathrm{mls}$ can be fatal. In Sri Lanka deaths due to paraquat resulting accidentally or as homicides are rare. Great majority of deaths due to paraquat results from ingestion with an intention of deliberate self-harm. It is the commonest herbicide that is self-ingested and the case fatality ratio is about $50-70 \%(8)$. Our data of patients aged 15 years and over admitted to Teaching Hospital Karapitiya from January 2007 to March 2009 show 162 admissions and 79 deaths giving a case fatality ratio of $49 \%$. Corresponding data that we have corrected from General Hospital, Matara show 70 admissions and 37 deaths giving a case fatality ratio of $53 \%$. However, these figures may be underestimates as those patients who went home prematurely against medical advice have been considered in the same category as those discharged home alive. We have not studied the number of deaths in the category of patients who went home against medical advice (unpublished data).

\section{INTEON study (8)}

There is no specific antidote against paraquat. Fuller's Earth which is a mixture of finely grained minerals offering a large surface for adsorption of paraquat is given to reduce its absorption from the stomach but its efficacy in paraquat poisoning is questionable. We embarked on a multicentre prospective observational study to test the efficacy of reducing mortality due to paraquat ingestion with a special formulation of paraquat manufactured by SYNGENTA called GRAMOXONE INTEON. The study was carried out at nine hospitals in Sri Lanka including Teaching Hospital Karapitiya where I was the Principal Coordinator. The study was funded by the SYNGENTACrop Protection Limited. 
Ethical approval was obtained from four ethical review bodies including the Ethical Review Committee of our Faculty. The study was done from December 2003 to January 2006. The new formulation GRAMOXONE INTEON was introduced to our market in October 2004. This formulation had a natural alginate which immediately gels in the acid environment of the stomach entrapping any paraquat that is in its vicinity. GRAMOXONE INTEON also incorporated an enhanced quantity of emetic to induce early vomiting as well as magnesium sulphate, which enabled purgation to cause rapid transit through the intestine, thereby reducing its absorption. A total of 774 patients were recruited of which 97 were not included in data analysis. There were 297 patients in the group that took GRAMOXONE STANDARD and 295 in the group that took GRAMOXONE INTEON. Patients were followed up for 3 months from the time of admission.

The conclusions of the study are given below along with the figure 2 (8).

- 3 months survival after ingestion of paraquat improved from $27.1 \%$ to $36.7 \%$ (difference $9.5 \%$ ) when comparing those who took GRAMOXONE STANDARD to those took the new preparation GRAMOXONE INTEON.

- There was improvement of median survival time from 2.3 days to 6.9 days with the new preparation (GRAMOXONE INTEON), giving a wider window of opportunity to make use of any advances in the therapy in the future.

- Improvement in Median Survival time from 0.9 days to 1.5 days among non-survivors in those who took GRAMOXONE INTEON, giving a wider window of opportunity to make use of any advances in the therapy in the future.

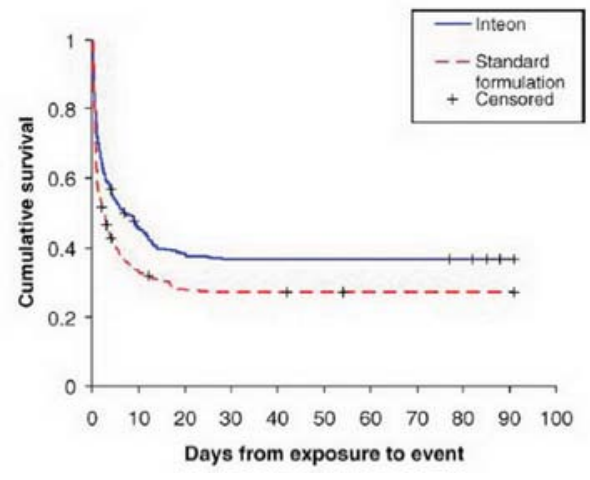

Figure 2 - Survival curve
However, the new preparations GRAMOXONE INTEON failed to have any impact on the survival of those who had taken it in larger quantities. Paraquat when taken in larger doses causes multi-organ failure and cardiogenic shock leading to rapid death.

\section{On going trials in paraquat poisoning that are conducted by the SACRTC}

Currently we are conducting a randomized controlled trial of immunosuppressive therapy in patients who have taken paraquat using intravenous methyl prednisolone and cyclophosphamide followed by dexamethasone to determine whether the incidence of pulmonary fibrosis can be reduced.

\section{Recent developments in sales of paraquat}

Considering our rather futile attempts to cut down the toxicity and the high fatality ratio, a decision was made by the pesticide regulatory authorities in Sri Lanka to stop importing $20 \%$ paraquat and instead allow only sales of $6.25 \%$ paraquat with effect from January 2008. Our recent unpublished data show a drop in case fatality ratio due to paraquat to around $50 \%$. We hope to evaluate this drop in case fatality ratio to see whether it is an effect of changing the concentration of paraquat to $20 \%$ to $6.25 \%$. In any case the good news is that importing paraquat is expected be banned in 3 years time.

\section{Kaneru poisoning}

Oleander (sinhala - kaneru) poisoning usually occur following deliberate ingestion of its seeds. Kaneru is highly poisonous and even ingesting a single seed can cause death. As seeds taste bitter most patients eat seeds after lacing it with sugar. All parts of oleander (sinhala - kaneru) plant are poisonous. This plant is often found in home gardens in the dry zones of Sri Lanka. Thevetia peruviana or yellow oleander is the commonest plant poison in Sri Lanka. As kaneru seeds contain highly toxic cardiac glycosides, wide variety of tachyarrhythmias and bradyarrhythmias occur following ingestion. In kaneru poisoning even asymptomatic patients are in great danger of developing heart block and cardiac arrest. Kaneru causes bradycardia with varying degrees of heart block and hypotension. Although anti-digoxin antibodies are effective in neutralizing the effect of glycosides in kaneru, it is very expensive and hence not readily available. 
Kaneru poisoning is common in the North Central Province and in Hambantota District. From January 2007 to April 2009 number of hospital admission and deaths due to Kaneru poisoning in three large hospitals in Southern Province are given in the table 1.

Out of 34 admissions with kaneru poisoning to Teaching Hospital, Karapitiya, 19 patients were transferred from General Hospitals, Matara and Hambantota. Out of admissions to these three hospitals, we observe a disproportionately high number of patients with kaneru poisoning in Hambantota Hospital. Once again, we observe an area specific phenomenon of poisoning due to one type of poison more than the others. A similar observation was made with washing powder (oxalic acid and potassium permanganate) poisoning which was predominant in Galle district compared to Matara and Hambantota districts. It is noteworthy that no patients with poisoning due to washing powder have been reported from the North Central Province during this period. Poisoning due to washing powder during the period October 2007 to
April 2009 in the three major hospitals in the Southern Province are given in the table 2.

Data collected by the SACTRC from Anuradhapura and Polonnaruwa Hospitals shows that there is a high incidence of kaneru poisoning in the North Central Province for years 2004-2007 as given in the table 3 .

It is alarming to note that oleander (kaneru) poisoning which was reported for the first time in 1979 to have escalated to the $4^{\text {th }}$ position in North Central Province and to the $7^{\text {th }}$ position in Sri Lanka with respect to hospital admissions due to poisoning (5).

\section{Paracetamol poisoning}

Poisoning due to drug overdose is the commonest cause of poisoning world over. Paracetamol leads the league table in drug overdose. This is a universal phenomenon and Sri Lanka is no exception to this observation. Our data (unpublished) collected during the period October 2007 to April 2009 given in the table 4 confirms this observation.

\begin{tabular}{|c|c|c|c|}
\hline Hospital & No. of patients & Deaths & Case fatality ratio $\%$ \\
\hline Galle (THK) & $34^{*}$ & 01 & 3.0 \\
\hline Matara & 66 & 0 & 0 \\
\hline Hambantota & 402 & 23 & 5.7 \\
\hline \multicolumn{4}{|c|}{ *19 transferred from Matara \& Hambantota } \\
\hline \multicolumn{4}{|c|}{$\begin{array}{l}\text { Table } 2 \text { - Poisoning with washing powder Admissions to three large hospitals in Southern } \\
\text { Province October } 2007 \text { - April } 2009\end{array}$} \\
\hline Hospital & \multicolumn{2}{|c|}{$\begin{array}{l}\text { No. of patients } \\
\end{array}$} & Deaths \\
\hline Galle & \multicolumn{2}{|c|}{146} & 4 \\
\hline Matara & \multicolumn{2}{|l|}{76} & 0 \\
\hline Hambantota & 0 & \multicolumn{2}{|r|}{0} \\
\hline \multicolumn{4}{|c|}{$\begin{array}{l}\text { Table } 3 \text { - Oleander (kaneru) poisoning Admissions to Anuradhapura \& Polonnaruwa Hospitals } \\
2004-2007(n=3011)\end{array}$} \\
\hline Year & 2004 & $2005 \quad 2006$ & 2007 \\
\hline No. of patients & 808 & 750 & 694 \\
\hline Deaths & 26 & 27 & 31 \\
\hline Hospital & No. of patients & $\begin{array}{l}\text { Percentage from } \\
\text { drug overdoses }\end{array}$ & $\begin{array}{l}\text { Percentage from } \\
\text { total cases poisoning }\end{array}$ \\
\hline Galle & 817 & 61 & 30.9 \\
\hline Matara & 337 & 57.2 & 24 \\
\hline Hambantota & 153 & 61.4 & 11.8 \\
\hline
\end{tabular}


We observe that there is a big burden on healthcare delivery services of Sri Lanka from paracetamol overdoses. Although none of the patients from this series of 1307 paracetamol overdose died, the amount of money that was spent on treating them by the state hospitals was colossal. A single overdose of more than 20 tablets $(>10 \mathrm{~g})$ is potentially fatal. Following an overdose of paracetamol exceeding $200 \mathrm{mg} / \mathrm{kg}$ body weight, its metabolic pathway in the liver gets overwhelmed due to glutathione depletion. As a result toxic metabolite of paracetamol accumulate causing cell damage in parenchymatous organs such as the liver, kidneys, heart and pancreas. Such damage begins around 10 hours after taking an overdose of paracetamol.

At this point I would like to mention another study we carried out by analysing admissions to Teaching Hospital, Karapitiya with acute poisoning from the beginning of 2002 to end of 2007 (14). There were 7111 admissions during this period, 3503 before and 3608 after the tsunami of 26 December 2004. There was an increase in the overdoses in the first quarter that followed the tsunami. As most overdoses were due to paracetamol we considered ready access to paracetamol which was given in ample quantities by aid agencies to be a possible cause for the increase overdoses besides post-tsunami stress.

However, several factors and co-morbid conditions such as malnutrition, alcohol abuse, enzyme inducing drugs and viral infections including HIV lower the threshold for developing toxicity in paracetamol overdose (9). We recently reported a case study of a patient who developed hepatotoxicity after taking only 12 tablets $(6 \mathrm{~g})$ of paracetamol following a 24 hour fast. $\mathrm{N}$-acetyl cysteine (NAC) and methionine protect the liver from paracetamol induced injury, if given early. Commencing methionine therapy is recommended preferably within 8 hours after ingestion if there is no vomiting (11). However it can be commenced up to 12 hours of ingestion of paracetamol. Although NAC too is recommended to be commenced within 8 hours of ingestion it can be given up to 24 hours of ingestion. It is recommended that continuation of therapy with NAC be based on a plasma paracetamol level done within first 24 hours, but not earlier than 4 hours.

In Sri Lanka no facilities are available for estimation of plasma paracetamol levels in state hospitals. In private hospitals in Colombo, paracetamol level estimation costs few thousands of rupees and results are not available within a short time. Furthermore, estimation of paracetamol in the private sector is known to give inconsistent results. Therefore, all patients who arrive in hospital after taking more than 20 tablets $(10 \mathrm{~g})$ of paracetamol are given antidotes as a routine. The cost of NAC per patient treated is around Rs. 14,000/-. The cost of methionine is much less, being just one fourth the cost of NAC. As a result, the Ministry of Health is spending several hundred millions of rupees for treating these patients every year even if we take only the cost of antidotes into consideration.

We feel that patients with paracetamol overdose are over treated and performing a routine paracetamol assay and thereby using antidotes only on patients who have toxic blood levels alone would save a large amount of money. We know that paracetamol has a very low case fatality rate as shown in our series of over 1000 patients. We find that patients generally do not take paracetamol with a suicidal intent. Often they seem to take paracetamol as a 'cry for help'. As such they take only few tablets but often exaggerate the quantities when they report to doctors. Although a patient may have taken a potentially toxic dose some of the tablets ingested may have been vomited or being taken out with a gastric lavage. Therefore, it is very important to determine the level of paracetamol in plasma as it would prevent over treating patients (12). Another way of cost cutting is to give methionine instead of NAC if the patient presents in less than 8 hours and he/she can takes it orally and retain it without vomiting.

Shihana HSF et al in the SACTRC at Peradeniya Centre have developed a cheap method of estimating paracetamol level within a short time (13). This has been validated against measurement of plasma paracetamol using high performance liquid chromatography (HPLC) and it costs around Rs.50/-. If this method of estimation can be routinely used by making the facility available in state sector hospitals, a large number of patients who would otherwise unnecessarily be given antidotes could avoid such therapy, saving a large amount of money. SACTRC has made a request to the Ministry of Health to consider adopting this inexpensive method of assaying plasma paracetamol in all hospitals.

At this point I would like to mention another study we carried out by analysing admissions to Teaching Hospital, Karapitiya with acute poisoning from the beginning of 2002 to end of 2007 (14). There were 
7111 admissions during this period, 3503 before and 3608 after the tsunami of 26 December 2004. There was an increase in the overdoses in the first quarter that followed the tsunami. As most overdoses were due to paracetamol we considered ready access to paracetamol which was given in ample quantities by aid agencies to be a possible cause for the increase overdoses besides post-tsunami stress.

\section{More trends in poisoning in the study population}

In our data on poisoning and deliberate drug overdoses collected at the Teaching Hospital, Karapitiya (THK) from January 2007 to March 2009 there were a total of 2549 patients and a breakdown of details are given in the table 5.

Although the table 5 accounts for causes of death in 110 patients, 34 more patients died during the same period due to poisoning giving a total of 144 deaths. Of these 34 deaths, 16 were accounted by other pesticides and the poisons in others 18 patients could not be elucidated. Among these 144 patients who died, five times more males died in comparison to females (121 males : 23 females). This could be explained on the fact that more males were taking paraquat (which has a high case fatality ratio). Out of 79 deaths due to paraquat, 69 were accounted by male deaths. The proportion of males (127) taking paraquat in comparison to females (35) was very high. In this series of patients the case fatality rate for paraquat in males and females is $54 \%$ and $29 \%$, respectively. This gender difference in case fatality ratio can be accounted by the small quantities of poison that may have been swallowed by females. The breakdown of data in paraquat poisoning patients is given in table 6 .
Of 776 patients with paracetamol overdose admitted to Teaching Hospital, Karapitiya from January 2007 to March 2009, 590 were females. Therefore, it seems that females who out number males by more than three times in taking overdoses of paracetamol and yet survive $100 \%$ to have taken the overdose more as a 'cry for help' than with suicidal intent. Even among those who take highly toxic poisons like paraquat and organophosphate there are many who regret having taken poison as an impulsive act (15). However, two case studies done in Sri Lanka have shown that in rural areas $10-20 \%$ of cases to have bought pesticides from agriculture outlets purposely for and immediately prior to self-harm ingestion $(15,16)$.

As mentioned earlier paracetamol was the commonest drug that was found to have caused drug overdose in our series. However, we found a variation in the number and proportion of paracetamol overdose cases in relation to the total number of poisoning patients across of three study hospitals viz. Teaching Hospital, Karapitiya, General Hospitals Matara and Hambantota as given in the table 7.

The decline in proportion paracetamol overdose patients in the Karapitiya Hospital through Matara Hospital to Hambantota Hospital may be related to socioeconomic and cultural factors as well as to the availability of paracetamol in the household. Poisons and drug overdoses are taken impulsively in Sri Lanka by subjects that are mainly in the prime of their youth. In our data collected at Teaching Hospital, Karapitiya more than half $(53.4 \%)$ who took poison were aged 15 to 24 years and only $12.2 \%$ were aged above 45 years.

Table 5 - Poisoning \& drug over overdose due to deliberate self-harm

Admissions to THK from January 2007 - March 2009 - unpublished data $(n=2549)$

\begin{tabular}{|c|c|c|c|c|c|c|}
\hline Type of poison & Paracetamol & $\begin{array}{c}\text { Other } \\
\text { medicines }\end{array}$ & Paraquat & $\begin{array}{c}\text { Organo } \\
\text { phosphate }\end{array}$ & $\begin{array}{c}\text { Washing } \\
\text { powder } \\
\text { (oxalic acid) }\end{array}$ & $\begin{array}{c}\text { Oleander } \\
\text { (kaneru) }\end{array}$ \\
\hline No. of patients & 776 & 512 & 162 & 129 & 146 & 34 \\
\hline No. of deaths & 0 & 03 & 79 & 23 & 04 & 01 \\
\hline Case fatality ratio\% & 0 & 0.3 & 49 & 18 & 2.7 & 2.9 \\
\hline \multicolumn{7}{|c|}{ Table 6 - Paraquat poisoning Admissions to THK from January 2007 - March 2009 (n=162) } \\
\hline Gender & \multicolumn{3}{|c|}{ Male } & \multicolumn{2}{|c|}{ Female } & \\
\hline No. of patients & \multicolumn{2}{|c|}{127} & \multicolumn{3}{|c|}{35} & \\
\hline No. of deaths & \multicolumn{2}{|c|}{69} & \multicolumn{3}{|c|}{10} & \\
\hline Case fatality ratio & \multicolumn{2}{|c|}{54} & \multicolumn{3}{|c|}{29} & \\
\hline
\end{tabular}


Table 7 - Paracetamol overdose patients January 2007 - March 2009 ( $\mathrm{n}=776)$

\begin{tabular}{l|l|l|l|l|l}
\hline Galle & \multicolumn{3}{|l|}{ Matara } & \multicolumn{2}{l}{ Hambantota } \\
\hline $\begin{array}{l}\text { No. of } \\
\text { patients }\end{array}$ & $\begin{array}{l}\text { Percentage from total } \\
\text { poisoning cases }\end{array}$ & $\begin{array}{l}\text { No. of } \\
\text { patients }\end{array}$ & $\begin{array}{l}\text { Percentage from total } \\
\text { poisoning cases }\end{array}$ & $\begin{array}{l}\text { No. of } \\
\text { patients }\end{array}$ & $\begin{array}{l}\text { Percentage from total } \\
\text { poisoning cases }\end{array}$ \\
\hline 776 & 30.5 & 321 & 24.5 & 144 & 11.7 \\
\hline
\end{tabular}

\section{Summary}

- Deliberate self poisoning is a major clinical and public health problem in Sri Lanka. Our data in Galle, Matara and Hambantota Hospitals from January 2007 to March 2009 confirms this statement.

- Most deaths due to self poisoning are caused by pesticides - paraquat and organophosphates, oleander (kaneru) and washing powder (oxalic acid and potassium permanganate).

- Paraquat has a very high case fatality ratio. In our 3 month follow up cohort of 297 patients who took GRAMOXONE STANDARD a case fatality ratio of $72 \%$ was seen.

- New formulation of paraquat GRAMOXONE INTEON with alginate technology has brought down case fatality ratio by $9.5 \%$ in comparison to the GRAMOXONE STANDARD formulation. It has also prolonged the average survival following paraquat ingestion from 2.3 days to 6.9 days enabling a wider window of opportunity in case therapeutic advances occur in the future for treatment of paraquat poisoning.

- Choice of poison in self-harm seems to depend on the geographical location it occurs as evident by washing powder (oxalic acid and potassium permanganate) poisoning occurring mainly in the Galle District and by oleander (kaneru) poisoning occurring mainly in the Hambantota District and the North Central Province. This may be due to a kind of 'trend setting'. However, the adverse effects that could arise from unwarranted media publicity too cannot be ignored.

- Large number of patients with paracetamol overdose was admitted to our study hospitals. Although it is reassuring to have zero mortality in patients with paracetamol overdose, we are faced with the dilemma of using large amounts of $\mathrm{N}$-acetyl cysteine and incurring a colossal expenditure to the health sector of the country for want of paracetamol assays to selectively treat only situations that are warranted.

\section{Recommendations and conclusions}

All recommendations given below are aimed at reducing the occurrence of poisoning by self-harm and in improving the survival and morbidity of patients who get admitted to hospitals with poisoning.

\section{Prevention:}

- The Government should give priority to alleviation of poverty and generation of employment.

- Import of highly toxic pesticides should be banned.

- Import, distribution and sale of moderately toxic pesticides should be controlled.

- Government should promptly ban marketing of unauthorized merchandise like washing powder with oxalic acid and potassium permanganate and take appropriate legal action for those who flout regulatory measures.

- Lockable storage devices should be made available in a concessionary manner to farmers to store pesticides away from homes.

- Psychiatric treatment including counseling should be made easily available to patients who are at a high risk of carrying out deliberate self-harm.

\section{Treatment:}

- Hospitals should be a better equipped and staffed, especially in the peripheries. This includes provision of emergency treatment units functioning over 24 hours, preferably 
Intensive Care Units with facilities for ventilation and cardiac pacing. Hospitals should always have an adequate stock of full range of antidotes for poisoning.

- Provision of more training for doctors and nurses in managing patients with poisoning. Emphasis should be made in the curricula of medical schools with respect to prevention and management of poisoning.

- Doctors should seek advice from the National Poisons Informatory Centre whenever it is necessary and they should adhere to guidelines given in the book by published by this centre in managing patients.

- Research and developments in the area of Clinical Toxicology should be encouraged and funded.

Loss of life due to poisoning by deliberate self-harm is truly unwarranted. We have to realize that many of those who die are in the prime of their youth with decades of normal and productive life ahead of them and we need to do everything possible to prevent these deaths.

\section{References}

1. Gunnell D, Eddleston M. Suicide by intentional ingestion of pesticides: a continuing tragedy in developing countries. Int J Epidemiol. 2003; 32(6): 902-9.

2. Where is the evidence for treatments used in pesticide poisoning? Is clinical toxicology fiddling while the developing world burns? Buckley N A, Karalliedde L, Dawson A, Nimal Senanayake, Eddleston M, Journal of Toxicology. Clinical Toxicology 2004; 42(1): 113-6.

3. Annual Health Bulletn, Ministry of Health, 2006.

4. The impact of pesticide regulations on suicide in Sri Lanka, Gunnell D, Fernando R, Hewagama M, Priyangika WDD, Konradsen F, Eddleston M, International Journal of Epidemiology 2007; 1-8.

5. Eddleston M, Ariaratnam CA, Meyer WP, Perera G, Kularatne AM, Attapattu S, Sheriff MH, Warrell DA. Epidemic of self-poisoning with seeds of the yellow oleander tree (Thevetia peruviana) in northern Sri Lanka. Trop Med Int Health 1999; 4(4):266-273.
6. Emerging epidemic of fatal human self-poisoning with a washing powder in Southern Sri Lanka: a prospective observational study. Gawarammana IB, Ariyananda PL, Palangasinghe C, de Silva NGL, Fernando Vidanapathirana KM, Kuruppuarachchi MA, Munasinghe MAAK, Dawson A H, Clinical Toxicology (Philadelphia, Pa.) 2009; 47(5):407-11.

7. Introna F Jr, Smialek JE. Antifreeze (ethylene glycol) intoxications in Baltimore. Report of six cases. Acta Morphol Hung 1989; 37(3-4): 245-263.

8. Wilks M F, Fernando R, Ariyananda P L, Eddleston M , Berry D J, Tomenson J A, Buckley N A, Jayamanne S, Gunnell D, Dawson A. Improvement in survival after paraquat ingestion following introduction of a new formulation in Sri Lanka, PLoS Medicine 2008; 5(2): e49.

9. Fernando R, In: Management of Poisoning. The National Poisons Information Centre, National Hospital of Sri Lanka, Colombo.

10. Kasun Fernando WKB, Ariyananda PL. Paracetamol poisoning below toxic level causing liver damage in a fasting adult. Ceylon Medical Journal 2009; 54(1): 16-7.

11. British National Formulary (BNF), 56: September 2008.

12. Decision Tree Modeling on the Antidotal Therapy of Acute Paracetamol Poisoning Management, Senarathna SMDKG, Sri Ranganathan S, Buckley N, Dawson A, Fernandopulle BMR, Asia Pacific Association of Medical Toxicology, $7^{\text {th }}$ Annual meeting, 7-10 December 2008, Chandigah, India.

13. Shihana HSF, Dissanayake AMSDM, Dargan PI, Dawson AH. A Modified Paracetamol Measurement Method and Measuring Plasma Paracetamol Concentrations in Patients With Drug Overdose, Asia Pacific Association of Medical Toxicology, $7^{\text {th }}$ Annual meeting, 7-10 December 2008, Chandigah, India.

14. A Study to Determine a Possible Effect of "Tsunami" On The Pattern of Admissions Due To Deliberate Self Poisoning in Galle District (poster), Palangasinghe C, Senarathna L, Ariyananda PL, Dawson AH, Asia Pacific Association of Medical Toxicology, $7^{\text {th }}$ Annual meeting, 7- 